\title{
0729. Interstitial changes in spleen during sepsis
}

\author{
ØS Svendsen ${ }^{1 *}$, L Stangeland ${ }^{2}$, B Elvevoll ${ }^{1,3}$, BT Gjertsen ${ }^{2}$, J Skavland ${ }^{2}$, H Wiig $^{4}$, O Tenstad ${ }^{4}$, P Husby ${ }^{1,3}$ \\ From ESICM LIVES 2014 \\ Barcelona, Spain. 27 September - 1 October 2014
}

\section{Introduction}

The spleen has important functions in innate and acquired immunological responses, and splenectomy leads to risk for overwhelming infections [1]. The microcirculation in spleen is only partly understood, and knowledge of the local interstitial fluid composition and changes during sepsis can offer new insights in the systemic inflammatory response syndrome.

\section{Objectives}

To isolate prenodal lymph from spleen in pigs during a control situation and during sepsis, and analyze the composition of proteins in the lymph.

\section{Methods}

Pigs were anesthetized and monitored. Plasma volumes were measured and the changes in hematocrit were, after corrected for the fluid gain and loss, used to estimate global plasma extravasation. One pre-nodal spleen lymphvessel was cannulated. LPS was administered to induce sepsis. Lymph and plasma were studied to investigate the specific local reaction in spleen during control situation and sepsis.

\section{Results}

Basal extravasation rate was $0.24 \pm 0.05 \mathrm{~mL} / \mathrm{kg}^{*} \mathrm{~min}^{-1}(\mathrm{n}=$ 4). Although technically demanding, we succeeded in collecting lymph from the spleen, deemed macroscopically to be prenodal. After inducing sepsis, pulmonary artery pressure increased from $19.0 \pm 2.2 \mathrm{mmHg}$ to $30.4 \pm 4.6$ mmHg one hour after LPS, $(\mathrm{n}=5, \mathrm{p}=0.001)$. Adrenaline and Ringer's acetate were administrated to support the animals through the inflammatory response. Plasma extravasation rate increased twofold to $0.53 \pm 0.04 \mathrm{~mL} /$ $\mathrm{kg}^{*} \min ^{-1}(\mathrm{n}=4, \mathrm{p}=0.003)$. Colloidosmotic pressure in plasma was $14.1 \pm 0.6 \mathrm{mmHg}$ in control situation, decreasing to $12.9 \pm 0.5 \mathrm{mmHg}(\mathrm{n}=4, \mathrm{p}=0.003)$ one hour after LPS. Colloidosmotic pressure in lymph was $13.0 \pm 1.7 \mathrm{mmHg}(\mathrm{n}=4)$ in control situation. During the first hours after sepsis, colloidosmotic pressure in spleen lymph decreased to $11.8 \pm 2.4 \mathrm{mmHg}(\mathrm{n}=3)$.

\section{Conclusions}

Our model shows typically hemodynamic changes previously described to be associated with an initial endotoxin reaction in pigs [2]. We show that it is possible to isolate lymph from spleen. The colloidosmotic pressures in lymph and plasma suggest a low protein reflection coefficient in spleen microvasculature.

\section{Grant acknowledgment}

Supported by The Western Norway Regional Health Authority.

\section{Authors' details}

${ }^{1}$ Haukeland University Hospital, Department of Anaesthesia and Intensive Care, Bergen, Norway. 'University of Bergen, Department of Clinical Science, Bergen, Norway. ${ }^{3}$ University of Bergen, Department of Clinical Medicine, Bergen, Norway. ${ }^{4}$ University of Bergen, Department of Biomedicine, Bergen, Norway.

Published: 26 September 2014

\section{References}

1. Semaeva $E$, et al: Access to the spleen microenvironment through lymph shows local cytokine production, increased cell flux, and altered signaling of immune cells during lipopolysaccharide-induced acute inflammation. Journal of immunology 2010, 184:4547-4556.

2. Schmidhammer $\mathrm{R}$, et al: Infusion of increasing doses of endotoxin induces progressive acute lung injury but prevents early pulmonary hypertension in pigs. Shock 2006, 25:389-394.

doi:10.1186/2197-425X-2-S1-P51

Cite this article as: Svendsen et al:: 0729. Interstitial changes in spleen during sepsis. Intensive Care Medicine Experimental 2014 2(Suppl 1):P51. 